\title{
Comparison of the Structure and Aspects of the Proteinase-Binding Properties of Cystic Fibrotic $\alpha_{2}$-Macroglobulin with Normal $\alpha_{2}$-Marroglobulin
}

\author{
RONALD C. ROBERTS, ${ }^{(4())}$ LYNN P. NELLES, ${ }^{(38)}$ PHILIP K. HALL, ${ }^{(38)}$ GUY S. SALVESEN, ${ }^{(38)}$ AND \\ ELAINE MISCHLER
}

Marshfield Medical Foundation, Inc., Marshfield, Wisconsin; Strangeways Research Laboratory, Cambridge, England; and University of Wisconsin Cystic Fibrosis Center, Madison, Wisconsin, USA

\begin{abstract}
Summary
Considerable attention has been focused recently on $\alpha_{2}$-macroglobulin $\left(\alpha_{2} \mathrm{M}\right)$, a major endopeptidase inhibitor in blood plasma, as a possible source of the primary defect in cystic fibrosis (CF). We report here studies designed to compare the structure of $\mathrm{CF}$ $\alpha_{2} M$ with normal $\alpha_{2} M$ to determine if there is a difference. The physicochemical properties of purified $\alpha_{2} M$ as revealed by various electrophoretic techniques, covalent proteinase binding properties, and primary structural studies on a variety of partial hydrolyzates of $\mathrm{CF} \alpha_{2} \mathrm{M}$ and normal $\alpha_{2} \mathrm{M}$ are compared. These studies were carried out on eight different individual isolates of CF $\alpha_{2} \mathrm{M}$ and three age-matched normal $\alpha_{2} M$ preparations and $\alpha_{2} M$ isolated from fetal cord blood. Three properties of $\mathrm{CF} \alpha_{2} \mathrm{M}$ were studied by sodium dodecyl sulfate-polyacrylamide gel electrophoresis (SDS-PAGE): (1) the existence of four identically-sized subunits in the native molecule (10), (2) the cleavage of this subunit into fragments of approximately 100,000 daltons upon interaction with proteinases (10), and (3) the cleavage of an alkaline/heat sensitive bond to produce 120,000 and 60,000 dalton fragments (11). Both $\mathrm{CF}$ and normal $\alpha_{2} \mathrm{M}$ were cleaved to the extent of $79-87 \%$. CF $\alpha_{2} M$ behaves identically with normal $\alpha_{2} M$ with regard to all these properties. Salvesen and Barrett (24) have demonstrated that varying proportions of several $\left[{ }^{125} I\right]$-labeled proteinases form SDSstable, non-reducible links to normal $\alpha_{2} \mathrm{M}$. Two of the CF $\alpha_{2} \mathrm{M}$ preparations were studied to determine if similar covalent binding of proteinases occurred. The positions of the labeled and $\%$ of proteinase bound bands in SDS/reduced PAGE system were identical for normal $\alpha_{2} M$ and $C F \alpha_{2} M$. These results indicate that CF $\alpha_{2} \mathrm{M}$ behaves normally with regard to covalent binding of proteinases. Qualitative comparison of the peptide fragments separated by SDS-PAGE or isoelectric focusing of CF and normal $\alpha_{2} M$ produced by partial proteolysis with trypsin, chymotrypsin or Staphylococcus aureus $\mathrm{V}-\mathbf{8}$ proteinase did not reveal any differences unique to $\mathrm{CF} \alpha_{2} \mathrm{M}$. The cyanogen bromide fragmentation studies and the cysteine cleavage studies also indicated that no major change in the positions of methionyl residues or cysteinyl/cystinyl residues has occurred in CF $\alpha_{2} M$. The failure of all these different studies and those reported by others to demonstrate any differences between $\mathrm{CF}$ and normal $\alpha_{2} \mathrm{M}$ makes it highly unlikely that there is a primary defect in $\alpha_{2} M$ in CF.
\end{abstract}

\section{Speculation}

The abnormalities previously reported that are associated with $\alpha_{2}$-macroglobulin-proteinase complexes in cystic fibrosis do not arise from a primary defect in the structure of $\alpha_{2}$-macroglobulin.

Considerable attention has been focused recently on $\alpha_{2}$-macroglobulin $\left(\alpha_{2} \mathrm{M}\right)$, a major endopeptidase inhibitor in blood plasma, as a possible source of the primary defect in cystic fibrosis (CF).
Normal $\alpha_{2} \mathrm{M}$ is made up of four identical subunit polypeptide chains each with a relative molecular weight of 185,000 (32). The macromolecule is assembled into half molecules by linkage of pairs of the subunit chains by disulfide linkages and the half molecules are held together by noncovalent linkages, giving an intact molecule of 725,000 daltons (10). Alpha-2-macroglobulin inhibits the proteolytic activity of a wide variety of proteinases from all cases of endopeptidases. This inhibition is believed to occur by entrapment of the proteinases after cleavage of a proteolytic bond near the middle of one or more of the subunit chains $(3,10)$. The region in the subunit polypeptide where the proteolytic cleavage occurs has recently been named the "bait" region (24). Although proteinase-entrapped proteins show no activity towards large new substrates, they are still active toward low molecular weight substrates. The proteolytic cleavage, occurring upon binding and inhibition of proteinases, does not release any immunologically detectable fragments of $\alpha_{2} \mathrm{M}$ in in vitro experiments. However, these fragments can readily be detected by sodium dodecyl sulfate-polyacrylamide gel electrophoresis (SDS-PAGE) following the reduction of disulfide bonds in the presence of sodium dodecyl sulfate (SDS).

The studies leading to a suspected abnormality in $\mathrm{CF} \alpha_{2} \mathrm{M}$ are as follows. Wilson and Fudenberg (35) reported an apparent deficient proteolytic cleavage of $\alpha_{2} \mathrm{M}$ in CF plasma. This conclusion was reached after the demonstration of a quantitative deficiency of protein bands focusing at about $\mathrm{pH} 5.48$ in isoelectric focusing patterns of $\mathrm{CF}$ plasma proteins. These protein bands were isolated from normal plasma and found by immunologic techniques to be fragments of $\alpha_{2} \mathrm{M}$. These authors also reported reduced arginine esterase activity in activated CF plasma, which correlated with the deficiency of these bands on the isoelectric focusing gels. They suggested that $\mathrm{CF} \alpha_{2} \mathrm{M}$ did not react normally with endogenous proteolytic enzymes in plasma. Shapira et al. (28) then reported the absence of an $\alpha_{2} \mathrm{M}$-proteinase complex in CF plasma activated with chloroform-ellagic acid. A group of $\alpha_{2} \mathrm{M}$ arginine esterase complexes were isolated from normal ellagic acid-chloroform activated plasma. One of these isolated complexes was consistently missing in CF plasma, leading them to speculate that a molecular defect in either a proteinase with arginine esterase activity or in $\alpha_{2} \mathrm{M}$ itself existed in CF. Further studies by this group reported decreased proteinase complex formation of $\alpha_{2} \mathrm{M}$ in CF plasma (27) using papain, thrombin and trypsin. Since papain and trypsin are not endogenous plasma proteinases, they concluded that the endopeptidase binding defect must reside in the $\alpha_{2} \mathrm{M}$ molecule. Shapira et al. (30) then compared the interaction of trypsin with purified CF $\alpha_{2} \mathrm{M}$ and normal $\alpha_{2} \mathrm{M}$. The kinetic constants, $\mathrm{K}_{\mathrm{m}}$ and $\mathrm{K}_{\mathrm{i}}$, for trypsin $\alpha_{2} \mathrm{M}$ complexes for the hydrolysis of the low molecular weight substrate benzoyl-L-arginine suggested that $\mathrm{CF} \alpha_{2} \mathrm{M}$ had a lower binding affinity for trypsin. Gel filtration of the reduced SDS treated CF $\alpha_{2} M$ trypsin complexes indicated that a proteolytic cleavage of the subunits had not 
occurred. In addition, Shapira et al. (29) reported that CF $\alpha_{2} \mathrm{M}$ trypsin complexes did not break down with time upon incubation of normal $\alpha_{2} \mathrm{M}$ trypsin complexes in the same manner as normal $\alpha_{2} \mathrm{M}$ complexes. This phenomenon, however, has not been previously reported or confirmed for normal $\alpha_{2} \mathrm{M}$.

In contrast to these reports, others have not been able to substantiate abnormal $\alpha_{2} \mathrm{M}$-proteinase interactions in CF. In fact, Schidlow and Kueppers (25) found moderately enhanced binding of trypsin to $\alpha_{2} \mathrm{M}$ in CF plasmas as in other chronic lung diseases. Romeo et al. $(21,22)$ demonstrated the presence of antitrypsin antibodies in the plasma of CF patients on pancreatic enzyme therapy. These antitrypsin antibodies were found to compete with the binding of trypsin to $\alpha_{2} \mathrm{M}(23)$ but the binding of trypsin to $\alpha_{2} \mathrm{M}$ appeared to be normal. The normal proteolytic fragmentation of native CF $\alpha_{2} \mathrm{M}$ occurring upon inhibiting a proteinase has been reported by Burdon (5) and Parsons and Romeo (20).

Recently detailed studies on the electrophoretic heterogeneity of purified samples of $\alpha_{2} \mathrm{M}$ by Barrett et al. (2) and our laboratory (18) demonstrated under certain nondenaturing conditions of polyacrylamide gel electrophoresis (PAGE) have been reported. Two major electrophoretic forms, slow and fast, were found and it was established that the fast form was not able to bind and inhibit proteinases. The slow form is the native, "virgin" form of $\alpha_{2} \mathrm{M}$ present in fresh plasma. It can be converted to the fast form by interaction with proteinases, reaction with simple amines or by unknown factors during storage of plasma or during the isolation procedure. We have recently reported (18) that CF $\alpha_{2} \mathrm{M}$ behaves identically with normal $\alpha_{2} \mathrm{M}$ preparations with regard to electrophoretic heterogeneity and that knowledge of the relative amounts of slow and fast forms present in each preparation would be necessary to evaluate and compare proteinase binding properties of $\alpha_{2} \mathrm{M}$ preparations.

We report here studies designed to compare the structure of $\mathrm{CF}$ $\alpha_{2} \mathrm{M}$ with normal $\alpha_{2} \mathrm{M}$ to determine if there is a difference. The physicochemical properties of purified $\alpha_{2} \mathrm{M}$ as revealed by various electrophoretic techniques, covalent proteinase binding properties and primary structural studies on a variety of partial hydrolyzates of CF $\alpha_{2} \mathrm{M}$ and normal $\alpha_{2} \mathrm{M}$ are compared. These studies were carried out on eight different individual isolates of CF $\alpha_{2} \mathrm{M}$ and three age-matched normal $\alpha_{2} \mathrm{M}$ preparations. Similar studies were also carried out on $\alpha_{2} \mathrm{M}$ isolated from pooled fetal cord blood, which has been found to behave as normal adult $\alpha_{2} \mathrm{M}$ in all aspects of this study and was readily available in our laboratory.

\section{MATERIALS AND METHODS}

\section{CF PATIENTS AND NORMAL SUBJECTS}

CF plasma was obtained from patients seen at the CF Center of the University of Wisconsin Hospitals, Madison, WI. Clinical information characterizing their disease status is presented in Table 1. Appropriate informed consents were signed by the patients and their parents, if they were minors, for the drawing of the blood samples.

Blood was obtained from adult volunteers and a 12-year-old male at Marshfield for preparation of normal $\alpha_{2}$ M. Most compar-

Table 1. Clinical data on CF patients studied

\begin{tabular}{cccccc}
\hline $\begin{array}{c}\text { Patient } \\
\text { number }\end{array}$ & Age & $\begin{array}{c}\text { Sweat Na } \\
\mathrm{mEq} / 1\end{array}$ & $\begin{array}{c}\text { NIH } \\
\text { score }\end{array}$ & $\begin{array}{c}\text { Shwachman } \\
\text { score }\end{array}$ & $\begin{array}{c}\text { Pancreatic } \\
\text { enzyme therapy }\end{array}$ \\
\hline 1 & 20 & 105.5 & 89 & 85 & 7 Ilozyme/meal \\
2 & 21 & 104.8 & 85 & 80 & 11 Ilozyme/meal \\
3 & 26 & 123.0 & 74 & 70 & None \\
4 & 13 & 117.0 & 68 & N.D.' & 4 Pancrease/meal \\
5 & 22 & 76 & N.D. & 90 & None \\
6 & 29 & 94.7 & N.D. & 90 & 5 Viokase/meal \\
7 & 20 & 125.8 & 93 & 85 & None \\
8 & 36 & 130.5 & 66 & 60 & None \\
\hline
\end{tabular}

${ }^{1}$ N.D. $=$ not done. isons were also carried out on $\alpha_{2} \mathrm{M}$ isolated from normal pooled fetal cord blood.

Isolation of $\alpha_{2} M$. Blood samples were obtained from CF patients and normals by venipuncture into a plastic syringe containing $1 / 10$ volume of a $3.8 \%$ sodium citrate, $3 \%$ soybean trypsin inhibitor solution (Mann Research Laboratories, New York, NY) as described by Harpel (10). Plasma samples were stored at $4^{\circ} \mathrm{C}$ for varying times up to $3 \mathrm{wk}$ before processing. The $\alpha_{2} \mathrm{M}$ was isolated by chromatography on a $5 \times 90 \mathrm{~cm}$ Cibacron Blue Sepharose and gel filtration on a $2.5 \times 90 \mathrm{~cm}$ acrylamide agarose column (AcA22, LKB Instruments, Inc, Rockville, MD) as previously described (33). Various additional fractionation steps to remove small amounts of contaminants were applied as needed. These steps included haptoglobin removal by immunoabsorption on an antihaptoglobin-immunoglobulin Sepharose $4 \mathrm{~B}$ column $(2.6 \times 7.5 \mathrm{~cm})$ or adsorption and elution of $\alpha_{2} \mathrm{M}$ on a $\mathrm{Zn}$-chelate column as described by Kurecki et al. (15) to remove haptoglobins and other contaminants. The yields of $\alpha_{2} \mathrm{M}$ for these isolation procedures were in the range of $30-40 \%$ as previously indicated (33).

Purity of the final $\alpha_{2} \mathrm{M}$ preparations was assessed by PAGE (36) and two dimensional crossed immunoelectrophoresis using antihuman antisera (Behring Diagnostics, Somerville, NJ) (34). In addition, as the final criterion of purity and to establish the integrity of the subunit polypeptide chains, reduced $\alpha_{2} \mathrm{M}$ samples were examined by SDS-PAGE (7.5\% total polyacrylamide using $2.6 \%$ bis-acrylamide as crosslinker) (15). Samples showing only the 185,000 dalton subunits were used. This step assured that the samples have not undergone proteolytic cleavage during isolation. The purified $\alpha_{2} \mathrm{M}$ preparations were stored frozen $\left(-70^{\circ} \mathrm{C}\right)$ in 0.02 $\mathrm{M}$ sodium citrate, $\mathrm{pH} 6.5$ or as a freeze-dried powder from this buffer at $-20^{\circ} \mathrm{C}$ as recommended by Barrett et al. (2).

\section{ELECTROPHORESIS AND ISOELECTRIC FOCUSING PROCEDURES}

$P A G E$. PAGE under nondenaturing conditions was carried out either by the discontinuous gradient technique using the trisEDTA-borate buffer or in 5\% polyacrylamide gels containing $5 \%$ crosslinker in tris-borate buffer. Details of these procedures and protein staining with Coomassie Blue have previously been described by this laboratory (18). PAGE gels were used to evaluate purity of the preparations and the relative amounts of slow and fast forms of $\alpha_{2} \mathrm{M}$ present (18).

$S D S-P A G E$. Slab gel SDS-PAGEs were done by Laemmli's procedure (16) or by the modification of this procedure described by Cleveland et al. (7). The stock solutions and the preparation of the running and stacking gels were prepared following the directions provided by the suppliers of the electrophoresis equipment (Bio-Rad model 220, Bio-Rad Laboratories, Richmond, CA). Details of the concentration of acrylamides and the buffer systems are found in the figure legends. After standing overnight in aqueous $20 \%$ isopropanol/10\% acetic acid, the gels were stained with $0.2 \%$ Coomassie Blue R-250 (Eastman Kodak Co, Rochester, NY).

\section{PREPARATION OF ALKALINE-CLEAVED $\alpha_{2} \mathrm{M}$ SAMPLES FOR SDS-PAGE.}

Alkaline-cleavage of the $\alpha_{2} \mathrm{M}$ subunit was carried out by two procedures. The original procedure, used for the samples shown in Figure 1, were prepared by adding $1 \mu \mathrm{l}$ of $1 \mathrm{~N} \mathrm{NaOH}$ to $14 \mu \mathrm{l}$ of the $\alpha_{2} \mathrm{M}$ solution in $0.25 \mathrm{M}$ tris, $\mathrm{pH} \mathrm{7.0,0.1 \%} \mathrm{SDS.} \mathrm{Control}$ experiments in which the same proportion of $1 \mathrm{~N} \mathrm{NaOH}$ was added to the same buffer gave a final $\mathrm{pH}$ of 11.0. The samples were incubated at $37^{\circ} \mathrm{C}$ for $0.5 \mathrm{~h}$, then neutralized by addition of $1 \mu \mathrm{l}$ of $1 \mathrm{~N} \mathrm{HCl}$ and an equal volume of Laemmli's reducing buffer added $\mathrm{pH} 6.8$ (16) and placed in a boiling water bath for 1 min. Because of the variable extent of cleavage observed and lack of specific knowledge of the final $\mathrm{pH}$ of the samples, a second procedure was devised. In this procedure the $50 \mu \mathrm{l}$ samples were dissolved in a pH 12.0 buffer $\left(0.1 \mathrm{M} \mathrm{Na} \mathrm{HPO}_{4}, 0.1 \%\right.$ SDS $)$. Samples were incubated at $37^{\circ} \mathrm{C}$ for $15 \mathrm{~min}$, then dialyzed in a 
microdialyzer (Bethesda Research Laboratories, Rockville, MD) overnight against $0.1 \mathrm{M}$ tris, $0.1 \% \mathrm{SDS}, \mathrm{pH} 7.0$.

Isoelectric focusing on polyacrylamide gels (PAG-IEF). The various partial digests of $\alpha_{2} \mathrm{M}$ were examined by isoelectric focusing in $8 \mathrm{M}$ urea or in some cases by the nonequilibrium $\mathrm{pH}$ gradient electrophoresis technique (NEPHGE) of O'Farrell, et al. (19). The PAG-IEF system in $8 \mathrm{M}$ urea was described by Epstein and Wolff (8) and was carried out in cylindrical gels. The $\mathrm{pH}$ gradient of $\mathrm{pH}$ 2.8-9.1 was developed using the $\mathrm{pH}$ 3-10 ampholine mixture (LKB Instruments, Inc, Rockville, MD). The gel dimensions were $6.5 \times 125 \mathrm{~mm}$. The upper electrode chamber contained $0.02 \mathrm{M}$ $\mathrm{NaOH}$ and the lower chamber contained $0.01 \mathrm{M} \mathrm{H}_{3} \mathrm{PO}_{4}$. For the NEPGHE system, the upper and lower electrode chamber solutions were reversed. The gels from either of these two systems were stained with Coomassie Blue R-250 as described by Epstein and Wolff (8).

Covalent binding of proteinases to $C F \alpha_{2} M$. The covalent binding of the $\left[{ }^{125} \mathrm{I}\right]$-labeled proteinases, pancreatic elastase, trypsin and chymotrypsin, to two of the CF $\alpha_{2} \mathrm{M}$ samples was studied by the procedures described by Salvesen and Barrett (24). In these experiments, complexes were formed by allowing several $\left[{ }^{125} \mathrm{I}\right]$-labeled proteinases to react with a 2-4 M excess of CF $\alpha_{2} \mathrm{M}$ samples. The two $\mathrm{CF} \alpha_{2} \mathrm{M}$ preparations used for these experiments contained only the active slow electrophoretic form. After the residual proteinase activity was blocked with diisopropyl fluorophosphate, the complexes were denatured in SDS at $37^{\circ} \mathrm{C}$ for $30 \mathrm{~min}$. The resulting polypeptide chains were analyzed by SDS-PAGE to determine what proportion of the radioactive proteinase remained associated with $\alpha_{2} \mathrm{M}$ subunits indicating covalent bonding. The sources of the enzymes, labeling procedures, and gel electrophoresis techniques are as described by Salvesen and Barrett (24), except that the complexes were not purified by gel filtration. The complexes were examined on both nonreduced SDS gels and reduced SDS gels for comparison of patterns obtained with normal $\alpha_{2} \mathrm{M}$ complexes.

\section{POLYPEPTIDE CHAIN CLEAVAGE PROCEDURES}

Partial proteolysis. Partial proteolysis of $\alpha_{2} \mathrm{M}$ followed by SDSPAGE was carried out by the procedure described by Cleveland et al. (7). Equal volumes of $\alpha_{2} \mathrm{M}$ dissolved in $0.01 \mathrm{M}$ tris, $\mathrm{pH} 7.6$ were added to sample buffer $(0.25 \mathrm{M}$ tris, $\mathrm{pH} 6.8,1.0 \%$ SDS, $20 \%$ glycerol and $0.0002 \%$ bromphenol blue), and then brought to $100^{\circ} \mathrm{C}$ for $2 \mathrm{~min}$. After equilibration at $37^{\circ} \mathrm{C}$, various amounts of either porcine trypsin, Staphylococcus aureus $\mathrm{V}-8$ proteinase (both from Miles Laboratories, Elkhart, IN) and bovine $\alpha$-chymotrypsin, (Type VII, TLCK-treated, Sigma Chemical Co, St. Louis, MO) were added and incubated at $37^{\circ} \mathrm{C}$ for $30 \mathrm{~min}$. The $\alpha_{2} \mathrm{M}$ samples were digested with the following ratios of enzyme to $\alpha_{2} \mathrm{M}: 1: 2.5$, $1: 5,1: 10$, and 1:20. Comparisons of partial digests of CF $\alpha_{2} \mathrm{M}$ and normal $\alpha_{2} \mathrm{M}$ were always made on samples digested at the same time with the same enzyme solution. The $V-8$ proteinase contained 500 casein units/mg and the trypsin solution was determined to contain $44.9 \%$ active trypsin by active site titration (18). The chymotrypsin was reported by the supplier to contain 48 BTEE units/mg protein. Then 0.1 volume of $50 \% \beta$-mercaptoethanol (Sigma Chemical Co, St. Louis, MO) in $10 \%$ SDS was added to each sample. They were again brought to $100^{\circ} \mathrm{C}$ for $2 \mathrm{~min}$ to inactivate the proteolytic enzymes.

Cyanogen bromide cleavage. Cleavage of the $\alpha_{2} \mathrm{M}$ polypeptide chains at methionine residues was carried out by the cyanogen bromide digestion procedure of Gross and Witkop (9). Three to $3.5 \mathrm{mg}$ of $\alpha_{2} \mathrm{M}$, reduced and alkylated according to Bamburg et al. (1), were dissolved in $1 \mathrm{ml}$ of $70 \%$ formic acid. Twenty $\mu$ l of a $25 \%$ $\mathrm{CNBr}$ solution in $70 \%$ formic acid was added (approximately 50 times excess of $\mathrm{CNBr}$ ) and the sample incubated overnight at $37^{\circ} \mathrm{C}$. An additional $20 \mu \mathrm{l}$ of the $\mathrm{CNBr}$ solution were added and the incubation was continued for a total of $22 \mathrm{~h}$. The samples were then diluted 10 times with distilled water, freeze-dried, redissolved in $\mathrm{H}_{2} \mathrm{O}$ and refreeze-dried to remove unreacted $\mathrm{CNBr}$.

Cleavage at cysteine residues. Cleavage of the $\alpha_{2} \mathrm{M}$ polypeptide

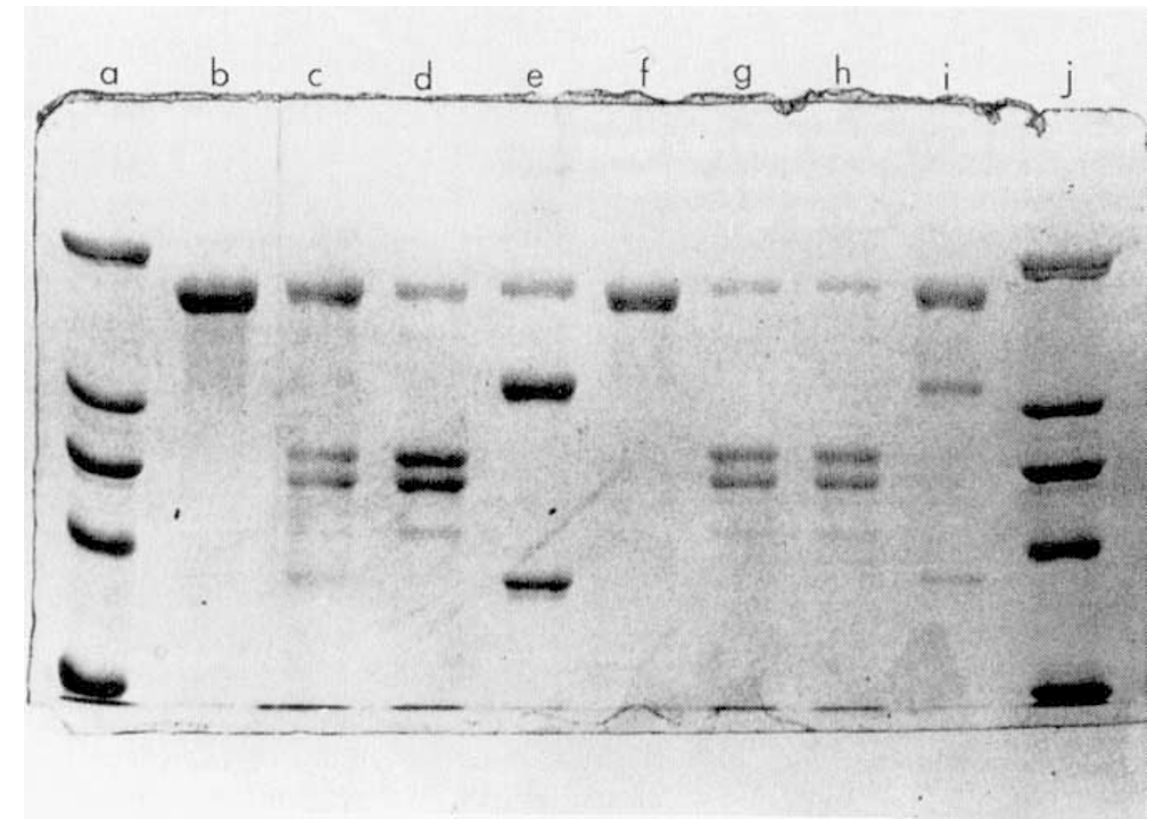

Fig. 1. Comparison of normal (fetal cord) $\alpha_{2} \mathrm{M}$ and CF $\alpha_{2} \mathrm{M}$ after reduction on SDS-PAGE after either no treatment, interaction with $S$. aureus $\mathrm{V}$ 8 proteinase, or heat treatment at alkaline $\mathrm{pH}$. The $0.75 \mathrm{~mm}$ running gel was $5 \%$ total polyacrylamide containing $2.6 \%$ cross-linker. The gel was run using the Laemmli system (15). Channels $a$ and $j$ are molecular weight standards (Bio-Rad high molecular weight protein standards, Bio-Rad Laboratories, Richmond, CA). The relative molecular weights of the bands in descending order are $200 \mathrm{~K}, 116 \mathrm{~K}, 94 \mathrm{~K}, 68 \mathrm{~K}$, and $43 \mathrm{~K}$. Channels $b$ and $f$ contain reduced normal $\alpha_{2} \mathrm{M}$ and $\mathrm{CF} \alpha_{2} \mathrm{M}$, respectively showing the single approximately $185 \mathrm{~K}$ subunit. Channels $c$ and $g$ contain normal and $\mathrm{CF} \alpha_{2} \mathrm{M}$, respectively which has interacted with 1 mole of $S$. aureus $\mathrm{V}-8$ proteinase per mole of $\alpha_{2} \mathrm{M}$; channels $d$ and $h$, normal and CF $\alpha_{2} \mathrm{M}$, respectively which has interacted with 1.5 moles of the V-8 proteinase per mole of $\alpha_{2} \mathrm{M}$. The proteinase was allowed to react with $\alpha_{2} \mathrm{M}$ in all cases for 3 min at room temperature before addition of the reducing buffer. Immediately upon addition of the reducing buffer, the samples were placed in a $100^{\circ} \mathrm{C}$ bath for 2 min. Channels $e$ and $i$ contain normal and $\mathrm{CF} \alpha_{2} \mathrm{M}$, respectively which have been exposed to alkali ( $\mathrm{NaOH}$ at approximately pH 11.0$)$ for 30 min at $37^{\circ} \mathrm{C}$ before reduction to effect limited cleavage of the heat/alkaline sensitive peptide bond. 
chains at cysteine residues was accomplished by the two step procedure described by Jacobson et al. (14). Samples of $\alpha_{2} \mathrm{M}$ containing $3.0-3.5 \mathrm{mg}$ were dissolved in $0.5 \mathrm{ml}$ of $0.1 \mathrm{M}$ tris, $8 \mathrm{M}$ urea solution ( $\mathrm{pH} 8.0$ ) containing $0.01 \mathrm{M} \beta$-mercaptoethanol and incubated at $37^{\circ} \mathrm{C}$ for $4 \mathrm{~h}$. An equal volume of the tris-urea buffer containing a 5 times excess (over the total sulfhydryl content) of 5,5'-dithiobis-(2-nitrobenzoic acid) (DTNB) was added. After 15 min, sufficient solid $\mathrm{KCN}$ was added to give a 10 times excess over the DTNB and allowed to stand $30 \mathrm{~min}$ at room temperature. After addition of $1 \mathrm{ml}$ of formic acid, the samples were dialyzed against $50 \%$ formic acid and freeze-dried. Cleavage was accomplished by solution of the samples in $120 \mathrm{mM}$ tris-glycine, $8 \mathrm{M}$ urea, $\mathrm{pH} 9.0$ for $12 \mathrm{~h}$ at $37^{\circ} \mathrm{C}$. The reaction was stopped by adding sufficient $\beta$-mercaptoethanol to bring its concentration to $1 \%$ $(\mathrm{v} / \mathrm{v})$.

Table 2. Quantitation of the extent of alkaline-cleavage of $C F$ and fetal cord $(F C) \alpha_{2} M$ samples

\begin{tabular}{cccc}
\hline & $\%$ & $\%$ & $\%$ \\
Sample source & $185 \mathrm{~K}$ subunit & $120 \mathrm{~K}$ fragment & $60 \mathrm{~K}$ fragment \\
\hline FC & 19 & 41 & 40 \\
FC & 13 & 42 & 45 \\
CF & 21 & 43 & 36 \\
CF & 18 & 43 & 39 \\
\hline
\end{tabular}

Table 3. Comparison of proportion of proteinases covalently linked to $C F$ and normal $\alpha_{2} M$

\begin{tabular}{lccc}
\hline & & \multicolumn{2}{c}{$\%$ covalently bound } \\
\cline { 3 - 4 } \multicolumn{1}{c}{ Proteinase } & Normal $\alpha_{2} \mathrm{M}$ & $\mathrm{CF}-1 \alpha_{2} \mathrm{M}$ & $\mathrm{CF}-2 \alpha_{2} \mathrm{M}$ \\
\hline Pancreatic & 31 & 35 & 32 \\
$\quad$ elastase & & & \\
Trypsin & 61 & 69 & 67 \\
Chymotrypsin & 62 & 58 & 63 \\
\hline
\end{tabular}

\section{RESULTS}

Comparisons of the properties of the subunits of CF and normal $\alpha_{2} M$ (Fig. 1). Three properties of CF $\alpha_{2} \mathrm{M}$ were studied by SDSPAGE: (1) the existence of four identically-sized subunits in the native molecule $(10),(2)$ the cleavage of this subunit into fragments of approximately 100,000 daltons upon interaction with proteinases (10), and ( 3 ) the cleavage of an alkaline/heat sensitive bond to produce 120,000 and 60,000 dalton fragments (11). With regard to these properties, a comparison between $\mathrm{CF} \alpha_{2} \mathrm{M}$ and normal $\alpha_{2} \mathrm{M}$, from either age-matched normals or fetal cord blood, shows that CF $\alpha_{2} \mathrm{M}$ behaves qualitatively identically to normal $\alpha_{2} \mathrm{M}$. In order to properly demonstrate all these properties, it is essential to start with $\alpha_{2} \mathrm{M}$ preparations showing only the slow electrophoretic form. Figure 1 shows a representative electrophoretogram in which these properties are compared for a CF $\alpha_{2} \mathrm{M}$ sample and a fetal cord $\alpha_{2} \mathrm{M}$ sample. Details of the various treatments of the samples are given in the Figure 1 legend. Note that this electrophoresis system separates the proteolytic fragments (channels $c, d, g$, and $h$ ) into fragments of relative molecular weights of 88,000 and 97,000 . Barrett et al. (2) has recently reported a similar separation of these fragments. We have examined six of the CF $\alpha_{2} \mathrm{M}$ preparations by these techniques and found that they behaved qualitatively identically as normal $\alpha_{2} \mathrm{M}$ with respect to these three properties. A markedly greater amount of alkaline-cleavage of the $185 \mathrm{~K} \alpha_{2} \mathrm{M}$ subunit was observed in the fetal cord $\alpha_{2} \mathrm{M}$ than seen for the CF $\alpha_{2} \mathrm{M}$ sample in this experiment (85\% versus $38 \%$ ). Since the small sample sizes precluded actual measurement of the $\mathrm{pH}$ of the alkaline-incubation, a second experiment was carried out with a pH 12.0 buffer (see "Materials and Methods") in which the same two $\alpha_{2} \mathrm{M}$ samples and an additional CF and fetal cord $\alpha_{2} \mathrm{M}$ sample were alkaline-cleaved. The extent of cleavage of these samples was determined by densitometry of the SDS-PAGE electrophoretogram. The results for these samples are given in Table 2 . The extent of cleavage of the CF $\alpha_{2} \mathrm{M}$ samples are essentially the same as those for the fetal cord $\alpha_{2} \mathrm{M}$ samples. The first fetal cord $\alpha_{2} \mathrm{M}$ sample and the first CF $\alpha_{2} \mathrm{M}$ sample listed in Table 2 are repeats of the samples shown in Figure $1, e$ and $i$ respectively.

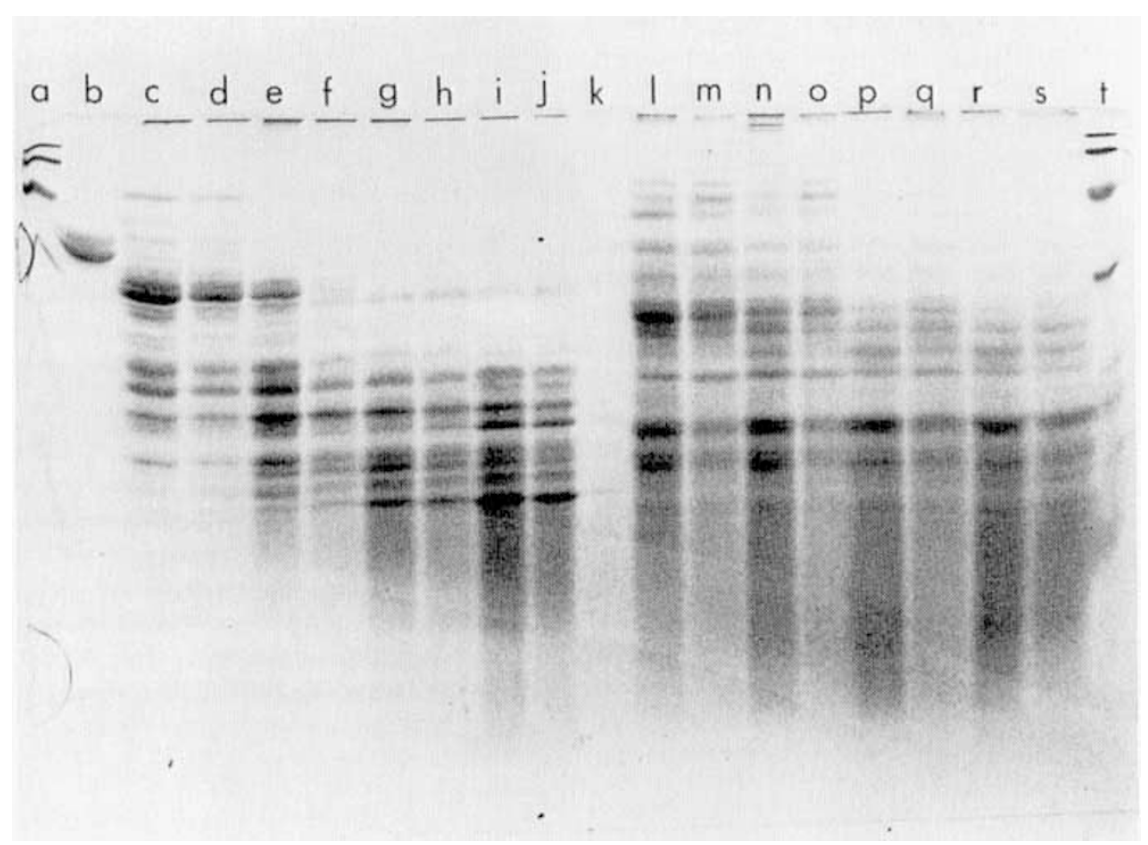

Fig. 2. SDS-PAGE separation of partial proteolytic digests of CF $\alpha_{2} \mathrm{M}(\mathrm{CF} \# 8)$ and normal $\alpha_{2} \mathrm{M}$ using a $15 \%$ polyacrylamide gel. Channels $a$ and $t$ contain molecular weight standards, distorted due to edge effects. Channel $b, S$. aureus V-8 proteinase; $c$ and $d$, normal and CF $\alpha_{2} \mathrm{M}$, respectively digested with a 1-20 weight ratio of V-8 proteinase to $\alpha_{2} \mathrm{M} ; e$ and $f$, normal and CF $\alpha_{2} \mathrm{M}$, respectively digested with a $1-10$ weight ratio of V-8 proteinase to $\alpha_{2} \mathrm{M} ; g$ and $h$, normal and CF $\alpha_{2} \mathrm{M}$, respectively digested with a 1-5 weight ratio of V-8 proteinase to $\alpha_{2} \mathrm{M} ; i$ and $j$, normal and CF $\alpha_{2} \mathrm{M}$, respectively digested with a $1-2.5$ weight ratio of $\mathrm{V}-8$ proteinase to $\alpha_{2} \mathrm{M} ; k$, porcine trypsin; $l$ and $m$, normal and CF $\alpha_{2} \mathrm{M}$, respectively digested with a $1-20$ weight ratio of trypsin to $\alpha_{2} \mathrm{M} ; n$ and $o$, normal and CF $\alpha_{2} \mathrm{M}$ digested with a 1-10 weight ratio of trypsin to $\alpha_{2} \mathrm{M} ; p$ and $q$, normal and CF $\alpha_{2} \mathrm{M}$, respectively digested with a 1-5 weight ratio of trypsin to $\alpha_{2} \mathrm{M} ; r$ and $s$, normal and CF $\alpha_{2} \mathrm{M}$, respectively digested with a $1-2.5$ weight ratio of trypsin to $\alpha_{2} \mathrm{M}$. 
Covalent binding of proteinases to $C F \alpha_{2} M$. Salvesen and Barrett (24) have demonstrated that varying proportions of several proteinases form SDS-stable, nonreducible links to normal $\alpha_{2} \mathrm{M}$. The stability of these links suggest that covalent bonds are formed between the proteinase and $\alpha_{2} \mathrm{M}$. Their results indicated that each subunit chain of $\alpha_{2} \mathrm{M}$ contains one such binding site. Two of the $\mathrm{CF} \alpha_{2} \mathrm{M}$ preparations were studied to determine if similar covalent binding of proteinases occurred. The $\%$ of $\left[{ }^{125} \mathrm{I}\right]$-labeled-pancreatic elastase, $\left[{ }^{[25} \mathrm{I}\right]$-trypsin and $\left.{ }^{125} \mathrm{I}\right]$-chymotrypsin covalently bound to CF $\alpha_{2} \mathrm{M}$ is compared with normal $\alpha_{2} \mathrm{M}$ in Table 3. This data was obtained by scanning the radioautographs of SDS gels run in the non-reduced system. The $\%$ of the three proteinases covalently linked were very similar to that bound to normal $\alpha_{2} \mathrm{M}$. The positions of the labeled bands in SDS/reduced PAGE system were identical for normal $\alpha_{2} \mathrm{M}$ and $\mathrm{CF} \alpha_{2} \mathrm{M}$. These results indicate that $\mathrm{CF} \alpha_{2} \mathrm{M}$ behaves normally with regard to covalent binding of proteinases.

\section{COMPARISON OF THE PEPTIDE PATTERNS PRODUCED BY VARIOUS} PARTIAL HYDROLYSIS METHODS

Partial proteolysis with trypsin, chymotrypsin and $S$. aureus $V-8$ proteinase. Partial digestion of SDS-treated $\alpha_{2} M$ samples were carried out with trypsin, chymotrypsin and $S$. aureus $\mathrm{V}-8$ proteinase using weight ratios of $\alpha_{2} \mathrm{M}$ to enzyme ranging from 1/2.5 to 1/ 20. The digestions were all carried out for $30 \mathrm{~min}$ at $37^{\circ} \mathrm{C}$.

Side by side comparisons of the SDS-PAGE peptide patterns obtained by digesting CF $\alpha_{2} \mathrm{M}$ and normal $\alpha_{2} \mathrm{M}$ with porcine trypsin and $S$. aureus $\mathrm{V}-8$ proteinase are shown in Figure 2. Four different $\mathrm{CF} \alpha_{2} \mathrm{M}$ preparations were compared with normal $\alpha_{2} \mathrm{M}$ samples in this manner using proteinases with three different types of specificity. Careful visual comparisons and densitometer tracings indicated that all bands were present, although differences in the quantitative amounts of some of the bands were found from sample to sample. None of these differences were unique to $C F$ $\alpha_{2} \mathrm{M}$ because similar variations were found when normal $\alpha_{2} \mathrm{M}$ samples were compared to each other or CF $\alpha_{2} \mathrm{M}$ samples were compared with each other. Thus, no differences from normal $\alpha_{2} \mathrm{M}$ in the molecular weights of the cleavage products resulting from partial proteolytic digestion of CF $\alpha_{2} \mathrm{M}$ were found.

The peptides resulting from partial proteolytic digestion of $\alpha_{2} \mathrm{M}$ by the $\mathrm{V}-8$ proteinase were also compared after separation by the NEPHGE method. An example of such a comparison is shown in Figure 3. In these separations, the peptides resulting from partial proteolysis are separated according to their isoelectric points. The NEPHGE system, which was used after normal isoelectric focusing procedures, did not yield good separation in the basic region of the gels. Three different pairs of CF $\alpha_{2} \mathrm{M}$ preparations were compared with normal $\alpha_{2} \mathrm{M}$ by this method. No differences were found between the focusing patterns for two of the pairs. Some differences were noted in the third pair in which a smaller amount of proteinase was used, in that one additional band, and several missing or much lighter bands were observed in the normal $\alpha_{2} \mathrm{M}$ digest. However, protein staining material remained at the top of this gel indicating the presence of high molecular weight material, unable to penetrate the gel. Thus, the differences noted are suspected to be due to unequal extents of digestion of the two samples in this experiment. No differences in the peptide patterns obtained by the NEPHGE method could be attributed to possible differences in the primary structure of CF $\alpha_{2} \mathrm{M}$.

Cleavage by cyanogen bromide. Samples of reduced and alkylated $\mathrm{CF}$ and normal $\alpha_{2} \mathrm{M}$ preparations were subjected to cyanogen bromide treatment which cleaves polypeptide chains at methionyl residues. The resulting peptide fragments were examined on both SDS-PAGE and PAGE-IEF gels. Usually 16-18 peptides were visualized. The theoretical number predicted for $\alpha_{2} \mathrm{M}$ if the four subunit chains are all identical would be 24 (32). Representative SDS-PAGE patterns comparing CF $\alpha_{2} \mathrm{M}$ and normal $\alpha_{2} \mathrm{M}$ patterns are shown in Figure 4, channels $a-e$. The patterns of the bands are indistinguishable from sample to sample indicating the fragments from CF $\alpha_{2} \mathrm{M}$ and normal $\alpha_{2} \mathrm{M}$ had similar molecular weights.

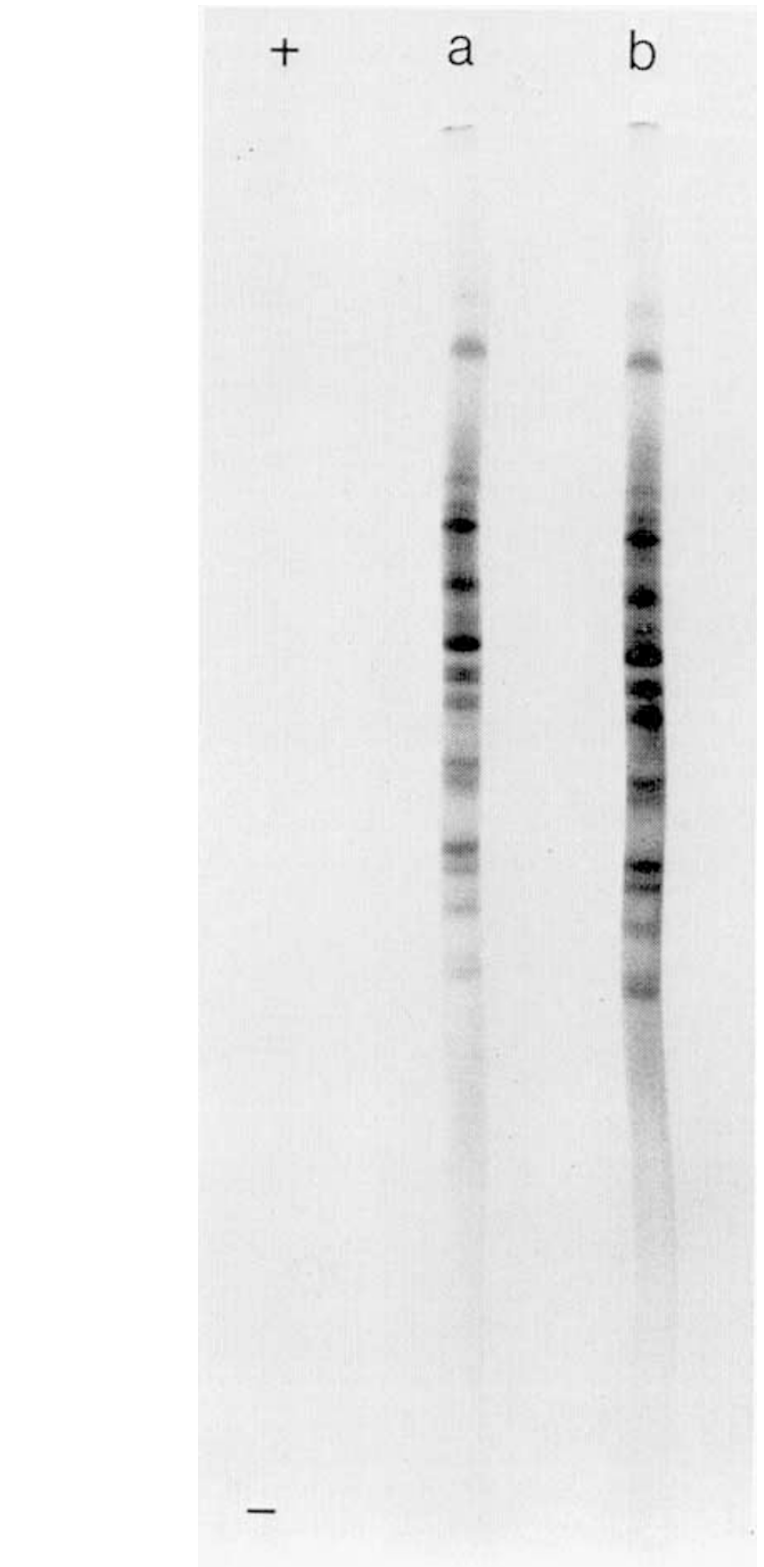

Fig. 3. Separation of peptides resulting from partial V-8 proteinase digests of $\mathrm{CF}$ and normal $\alpha_{2} \mathrm{M}$ samples by the NEPHGE method. Gels $a$, normal $\alpha_{2} \mathrm{M}$, and $b$, CF $\alpha_{2} \mathrm{M}$, both digested with a 1-5 weight ratio of enzyme to $\alpha_{2} \mathrm{M}$ for $30 \mathrm{~min}$ at $37^{\circ} \mathrm{C}$.

The cyanogen bromide fragments were also examined on PAGEIEF gels to see if any differences in their isoelectric points occurred. The patterns obtained for two pairs of $\mathrm{CF}$ and normal $\alpha_{2} \mathrm{M}$ preparations are shown in Figure 5. All patterns were practically identical. An extra band occurs at the top of the gel (basic end) in gels $a$ (a CF $\alpha_{2} \mathrm{M}$ ) and $d$ (a normal $\alpha_{2} \mathrm{M}$ ). This band probably represents a fragment that was not completely cleaved and its migration was slowed by molecular sieving. Because this extra band occurred in both normal and CF $\alpha_{2} \mathrm{M}$ samples, it cannot be CF related. Densitometer tracings of these gels confirmed the high degree of qualitative and quantitative similarity of these gels.

Cleavage at cysteine residues. The polypeptide chains of reduced $\alpha_{2} \mathrm{M}$ were cleaved at cysteinyl residues by treatment with DTNB and $\mathrm{KCN}$ (13). The resulting fragments were separated either by SDS-PAGE (Fig. $4, f-j$ ) or PAGE-IEF (Fig. 6). For the gel run illustrated, a mixture of two CF $\alpha_{2} \mathrm{M}$ digests and two normal $\alpha_{2} \mathrm{M}$ digests were combined in $a$ and $b$ to provide adequate sample loads. We have no explanation for the differences between the 


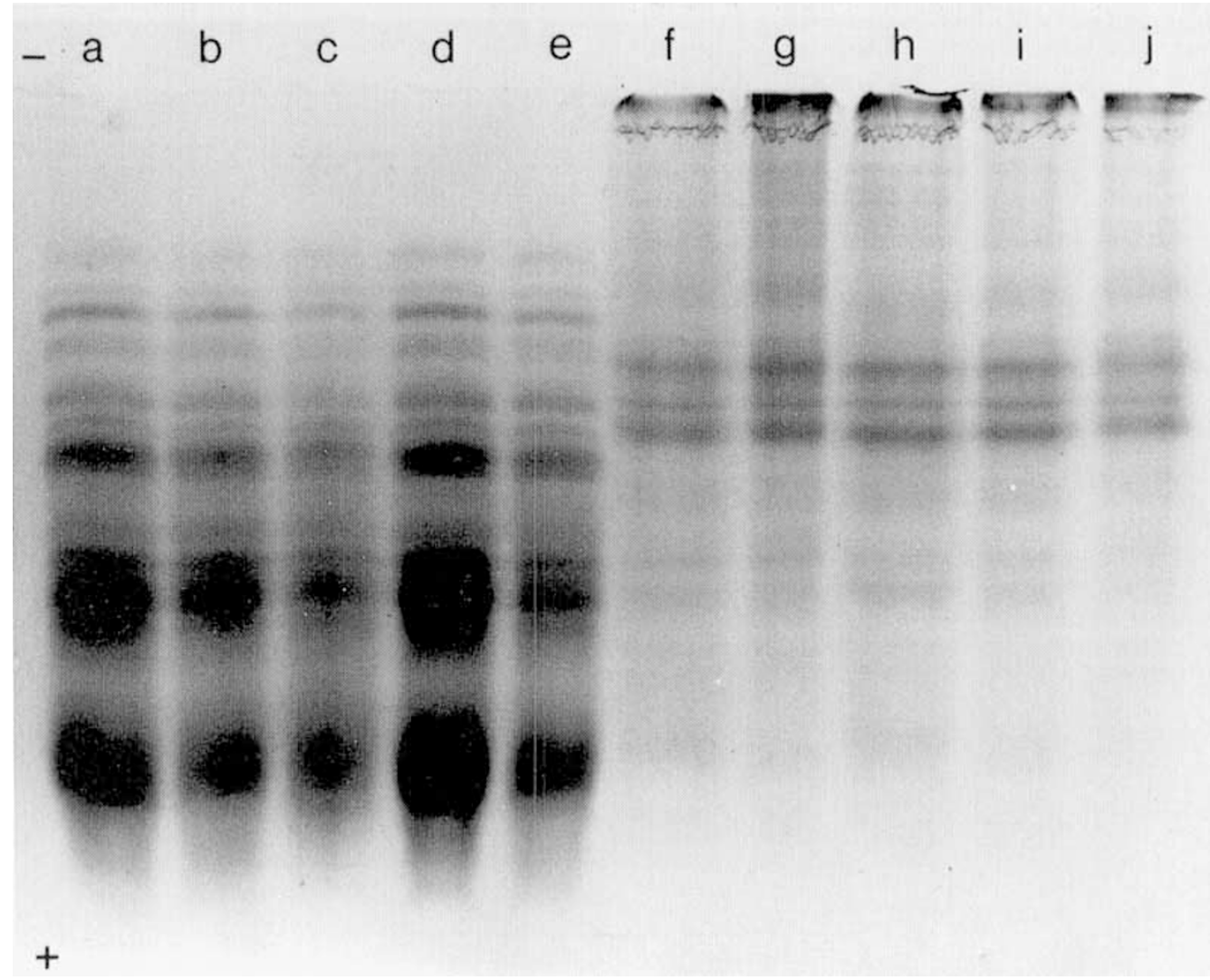

Fig. 4. SDS-PAGE gel containing polypeptide fragments of CF and normal $\alpha_{2} \mathrm{M}$ produced by cyanogen bromide digestion and cleavage at the cystienyl residues of reduced $\alpha_{2} \mathrm{M}$. The gel is $18 \%$ polyacrylamide run by the Laemmli system (15). Channels $a-e$ are cyanogen bromide fragments; $f-j$ are cystienyl cleavage products. a) CF $\alpha_{2} \mathrm{M} \# 3$ b) CF $\alpha_{2} \mathrm{M} \# 1$ c) Normal $\alpha_{2} \mathrm{M}$ (adult) d) CF $\alpha_{2} \mathrm{M} \# 4$ e) Normal $\alpha_{2} \mathrm{M}$ (juvenile) f) CF $\alpha_{2} \mathrm{M} \# 5$ g) CF $\alpha_{2} \mathrm{M} \# 1$ h) Normal $\alpha_{2} \mathrm{M}$ (adult) i) CF $\alpha_{2} \mathrm{M} \not 44$ j) Normal $\alpha_{2} \mathrm{M}$ (juvenile).

patterns in gels $a$ and $b$ as compared with $c$ and $d$. Since $a$ is compared with $b$ and $c$ compared with $d$, and no differences were noted, CF and normal $\alpha_{2} \mathrm{M}$ were qualitatively identical in each of the two experiments. Twenty to 22 bands were distinguishable after this treatment. Again, no differences between the $\mathrm{CF}$ and normal $\alpha_{2} \mathrm{M}$ samples attributable to $\mathrm{CF}$ were found.

\section{DISCUSSION}

The behavior of CF $\alpha_{2} \mathrm{M}$ polypeptide chains on SDS-PAGE after either reduction, reaction with proteinase, then reduction and heat treatment at alkaline $\mathrm{pH}$ was found to be identical with normal $\alpha_{2} \mathrm{M}$. These experiments indicate that all the known features of the quaternary structure of $\alpha_{2} \mathrm{M}$ related to its proteinaseinhibiting function are similar in CF $\alpha_{2} \mathrm{M}$ and normal $\alpha_{2} \mathrm{M}$. These results indicate that $\mathrm{CF} \alpha_{2} \mathrm{M}$, like normal $\alpha_{2} \mathrm{M}(10)$, is made up of four 185,000 dalton subunit chains which undergo proteolytic cleavage near the middle upon reacting with various proteinases. We have used trypsin, $S$. aureus V-8 proteinase, pancreatic elastase, and chymotrypsin over a range of mole ratios of $1: 1$ to $2: 1$ (proteinase: $\alpha_{2} \mathrm{M}$ ) and found comparable extents of production of the $88,000-97,000$ dalton fragments. These results confirm recent reports by Burdon (5) and Parsons and Romeo (20) that the subunit chains and the proteolytic fragmentation in the "bait" region occurs normally in $\mathrm{CF} \alpha_{2} \mathrm{M}$. The existence of the heat/ alkaline sensitive peptide bond (11) in CF $\alpha_{2} \mathrm{M}$ has also been demonstrated in our studies by showing the production of the 60,000 and 120,000 dalton fragments of the subunit chains by SDS-PAGE after appropriate treatment. Sottrup-Jensen et al. (31) and Howard (12) have recently reported that a thioester bond between a glutamic acid residue and a cystiene residue separated by two other amino acid residues causes the heat/alkaline peptide bond cleavage at the involved glutamic acid residue. Our results showing similar heat/alkaline bond cleavage in CF $\alpha_{2} \mathrm{M}$ indicates that this feature is also normal in CF $\alpha_{2} \mathrm{M}$. This thioester bond is also the alkylamine sensitive site (13), which is cleaved upon binding of proteinases. This is a further indication that $\mathrm{CF} \quad \alpha_{2} \mathrm{M}$ has the appropriate structures necessary to inhibit proteinases normally.

Another feature of proteinase- $\alpha_{2} \mathrm{M}$ interaction which has recently been delineated by Salvesen and Barrett (24) is the nonreducible, SDS-stable interaction of proteinases with $\alpha_{2} \mathrm{M}$. This has been interpreted as the formation of covalent bonds between $\alpha_{2} \mathrm{M}$ and proteinases at sites away from their catalytically active sites. Using the same procedures, we have demonstrated that the same "covalent" bonding occurs to the same extent when CF $\alpha_{2} \mathrm{M}$ samples are used. This represents a further demonstration of the normal interaction of $\mathrm{CF} \alpha_{2} \mathrm{M}$ with proteinases.

Comparison of the peptide fragments of CF and normal $\alpha_{2} \mathrm{M}$ produced by partial proteolysis with trypsin, chymotrypsin or $S$. aureus V-8 proteinase in the presence of SDS did not reveal any differences unique to CF $\alpha_{2} M$. Peptide maps, separated both on the basis of molecular size and charge, were compared. The specificities of the proteinases used are: trypsin primarily cleaves peptide bonds adjacent to the basic amino acid residues, arginyl and lysinyl; chymotrypsin prefers peptide bonds adjacent to phenylalaninyl and tyrosinyl residues; and $S$. aureus V-8 proteinase cleaves bonds adjacent to glutamyl and aspartyl residues. The close similarity in the peptide maps of the partial hydrolyzates between $\mathrm{CF}$ and normal $\alpha_{2} \mathrm{M}$ requires that all of these residues are close to the same positions in both types of $\alpha_{2} \mathrm{M}$. The identical patterns of the NEPHGE gels or the PAGE-IEF gels used to separate fragments produced by chemical cleavage also indicate that it is highly unlikely that a neutral/charged amino acid substitution has occurred. 
The cyanogen bromide fragmentation studies and the cysteine cleavage studies also indicated that no major changes in the positions of methionyl residues or cysteinyl/cystinyl residues has occurred in CF $\alpha_{2} \mathrm{M}$.

The electrophoretic methods used for peptide mapping of the various partial hydrolyzates prepared in this study are practical for carrying out a large number of side by side comparisons as was done in this study; however, when dealing with a protein with a very long polypeptide subunit such as $\alpha_{2} \mathrm{M}$, it is recognized that they do have limited resolving power for the detection of conservative amino acid substitutions. It is, therefore, not possible to rule out such substitutions and state that the primary amino acid sequence of CF $\alpha_{2} \mathrm{M}$ is identical to normal $\alpha_{2} \mathrm{M}$. When all these different studies are taken in conjunction with the failure of comparative studies of the quaternary structure and proteinase interaction reported here and by others (6) to demonstrate any differences between $\mathrm{CF}$ and normal $\alpha_{2} \mathrm{M}$, it makes it highly unlikely that there is a primary defect in CF $\alpha_{2} \mathrm{M}$.

Reconciliation of these results with the abnormalities reported in CF $\alpha_{2} \mathrm{M}$ by Shapira et al. (28) and abnormal fragmentation of $\alpha_{2} \mathrm{M}$ in CF plasma reported by Wilson and Fudenberg (35) is difficult. One possibility is that CF patients selected for the isolation of $\alpha_{2} \mathrm{M}$ may have been suffering from greater complications of their disease than those supplying blood samples for our study. Blood samples for this study were obtained from CF patients who were relatively healthy at the time of sampling. The CF $\alpha_{2} \mathrm{M}$ could possibly be altered during acute or chronic infections by in vivo products of such infections, particularly proteinases

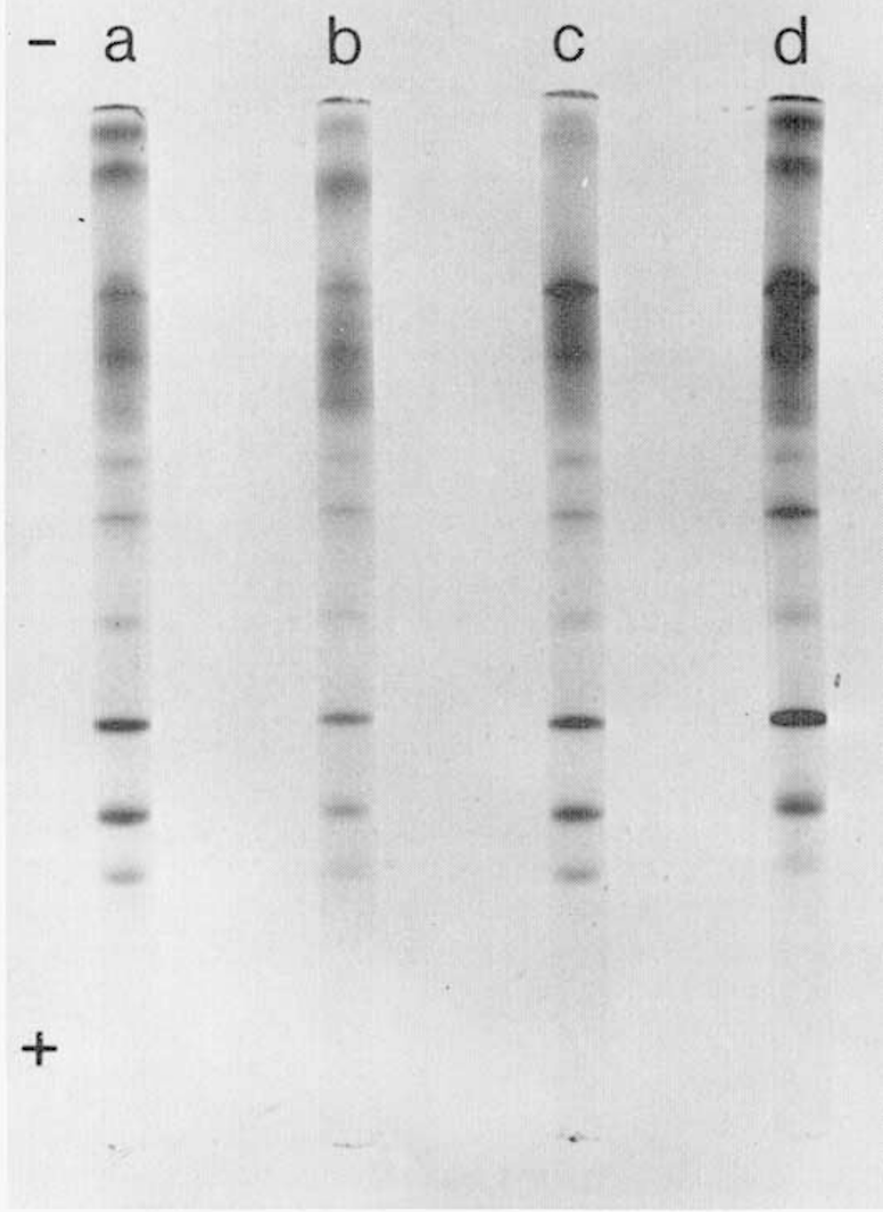

Fig. 5. PAGE-IEF gels comparing cyanogen bromide digests of normal and CF $\alpha_{2} \mathrm{M}$ samples. a) $\mathrm{CF} \alpha_{2} \mathrm{M}(\mathrm{CF} \# 3)$ b) Normal $\alpha_{2} \mathrm{M}$ (adult) c) CF $\left.\alpha_{2} \mathrm{M}(\mathrm{CF} \# 4) d\right)$ Normal $\alpha_{2} \mathrm{M}$ (juvenile).

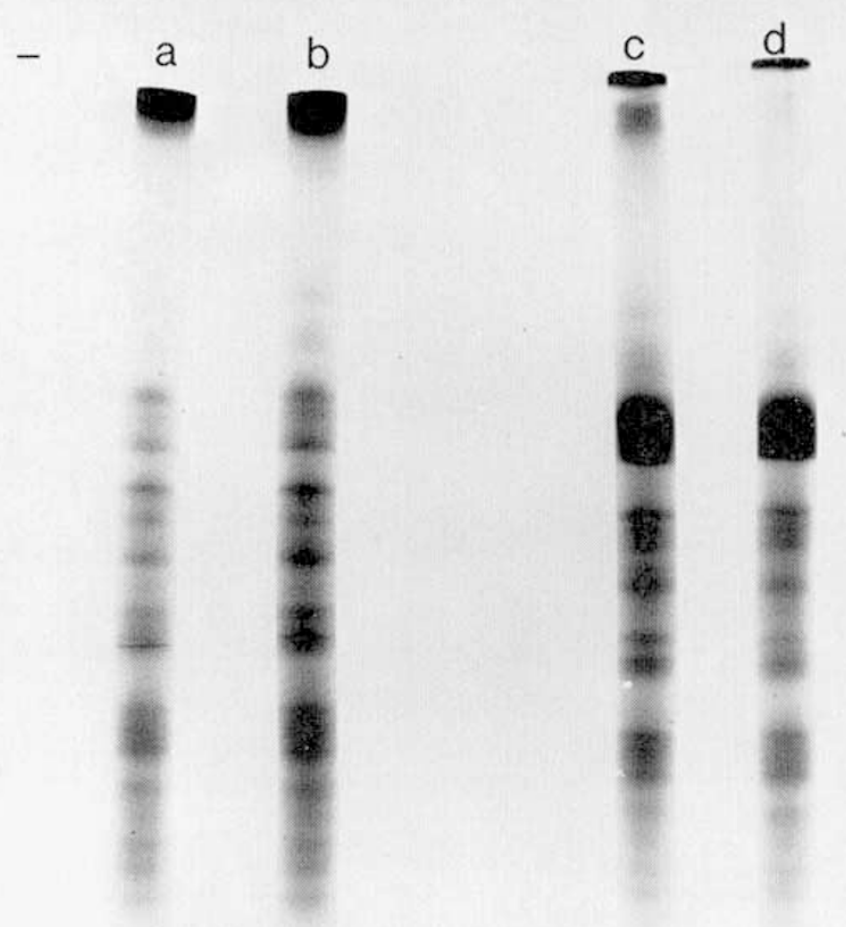

$+$

Fig. 6. PAGE-IEF gels comparing the cystienyl cleaved fragments of normal and $\mathrm{CF} \alpha_{2} \mathrm{M}$ samples. a) $\mathrm{CF} \alpha_{2} \mathrm{M}(\mathrm{CF} \# 1$ and $\mathrm{CF} \# 5$ ) b) Normal $\alpha_{2} \mathrm{M}$ (adult + juvenile $c$ ) $\mathrm{CF} \alpha_{2} \mathrm{M}(\mathrm{CF} \# 4) d$ ) Normal $\alpha_{2} \mathrm{M}$ (adult).

released by the inflammatory reaction. The test for such interaction, SDS-PAGE of reduced $\alpha_{2} \mathrm{M}$ or examination of the electrophoretic microheterogeneity of intact native $\alpha_{2} \mathrm{M}$ was not reported by these workers. Seven of the eight $\mathrm{CF}$ patients used in this study were on pancreatic enzyme therapy, ruling out this possible source of proteinase interaction (22) altering $\alpha_{2} \mathrm{M}$.

The possibility of genetic heterogeneity in $\mathrm{CF}$ has been raised by a number of workers over the years (17). Because of the relatively large samples of blood required to obtain enough $\alpha_{2} \mathrm{M}$ for these studies, we have selected older CF patients who were relatively healthy at the time of sampling, the possibility exists that we have inadvertently selected a subpopulation of cystic fibrotics who exhibit normal $\alpha_{2} \mathrm{M}$. We believe this possibility is remote because of the number of different patients studied and the fact that two of the patients have a sibling who are experiencing greater clinical problems at a younger age suggesting their mild course is not genetically linked. Sufficient information about the clinical status of patients from whom abnormal $\alpha_{2} \mathrm{M}$ was isolated for comparison with our group was not reported.

This study has not addressed the possibility that altered carbohydrate side chains of $\alpha_{2} \mathrm{M}$ may occur in CF $\alpha_{2} \mathrm{M}$ as has been recently suggested by others $(4,26)$. However, such alterations, if they exist, do not appear to affect the major structural features of $\alpha_{2} \mathrm{M}$.

\section{REFERENCES AND NOTES}

1. Bamburg, J. R., Shooter, E. M., and Wilson, L.: Assay of microtubule protein in embryonic chick dorsal root ganglia. Neurobiology. 3: 162 (1973).

2. Barrett. A. J., Brown, M. A., and Sayers, C. A.: The electrophoretic "slow" and "fast" forms of the $\alpha_{2}$-macroglobulin molecule. Biochem. J., 181: 401 (1979).

3. Barrett, A. J. and Starkey, P. M.: The interaction of $\alpha_{2}$-macroglobulin with proteinases. Characteristics and specificity of the reaction and a hypothesis concerning its molecular mechanism. Biochem. J., 133: 709 (1973).

4. Ben-Yoseph. Y., Defranco, C. L.. and Nadler, H. L.: Decreased sialic acid and altered binding to lectins of purified $\alpha_{2}$-macroglobulins from patients with cystic fibrosis. Clin. Chim. Acta, 99: 31 (1979). 
5. Burdon, M. G.: Normal subunit cleavage of alpha-2-macroglobulin in cystic fibrosis. Clin. Chim. Acta, 100: 225 (1980).

6. Choy, H., Applegarth, D. A., Davidson, A. G. F., and Wong, L. T. K.: Antiplasmin ( $\alpha_{2}$-macroglobulin) activity of plasma from cystic fibrosis patients. Biochem. Biophys. Res. Commun., 82: 1325 (1978).

7. Cleveland. D. W., Fischer, S. G., Kirschner, M. W., and Laemmli, U. K.: Peptide mapping by limited proteolysis in sodium dodecyl sulfate and analysis by gel electrophoresis. J. Biol. Chem., 252: 1102 (1977)

8. Epstein, H. F. and Wolff, J. A.: Peptide mapping of contractile proteins: two dimensional analysis of cyanogen bromide fragments on polyacrylamide gels. Anal. Biochem., 76: 157 (1976).

9. Gross, E. and Witkop, B.: Nonenzymatic cleavage of peptide bonds: the methionine residues in bovine pancreatic ribonuclease. J. Biol. Chem., 237: 1856 (1962).

10. Harpel, P. C.: Studies on human plasma $\alpha_{2}$-macroglobulin-enzyme interactions. Evidence for proteolytic modification of subunit chain structure. J. Exp. Med. I38: 508 (1973).

11. Harpel, P. C., Hayes, M. B., and Hugli, T. E.: Heat induced fragmentation of human $\alpha_{2}$-macroglobulin. J. Biol. Chem., 254: 8669 (1979).

12. Howard, J. B.: Reactive site in human $\alpha_{2}$-Macroglobulin: Circumstantial evidence for a thioester. Proc. Natl. Acad. Ser. USA, 78: 2235 (1981).

13. Howard, J. B., Vermeulen, M., and Swenson, R. P.: The temperature sensitive bond in human $\alpha_{2}$-macroglobulin is the alkylamine-reactive site. J. Biol. Chem., 255: 3820 (1980).

14. Jacobson, G. R., Schaffer, M. H., Stark, G. R., and Vanaman, T. C.: Specific chemical cleavage in high yield at the amino peptide bonds of cystiene and cystine residues. J. Biol. Chem., 248: 6583 (1973).

15. Kurecki, T., Kress, L. F., and Laskowski, M.: Purification of human plasma $\alpha_{2^{-}}$ macroglobulin and $\alpha_{1}$-proteinase inhibitor using zinc chelate chromatography. Anal. Biochem., 99: 415 (1979).

16. Laemmli, U. K.: Cleavage of structural proteins during the assembly of the head of bacteriophage T4. Nature, 227: 680 (1970).

17. Nadier, H. L., Rayo, G. J. S., and Taussig, L. M.: Cystic fibrosis. In: Stanbury, J. B., Wyngaarden, J. B., and Fredrickson, D. S. (Eds): The Metabolic Basis of Inherited Disease, pp. 1682-1710 (McGraw-Hill Book Company, 4th edition, New York, NY 1973).

18. Nelles, L. P., Hall, P. K., and Roberts, R. C.: Human alpha-2-macroglobulin. Studies on the electrophoretic heterogeneity. Biochim. Biophys. Acta, 623: 46 (1980).

19. O'Farrell, P. Z., Goodman, H. M., and O'Farrell, P. H.: High resolution twodimensional electrophoresis of basic as well as acidic proteins. Cell, 12: 1133 (1977)

20. Parsons, M. and Romeo, G.: Cystic fibrosis $\alpha_{2}$-macroglobulin protease interaction in vitro. Clin. Chim. Acta, 100: 215 (1980).

21. Romeo, G., Parsons, M., Bossen, A., Blessing-Moore, J., and Cavalli-Sforza, L.: Trypsin-binding IgG in cystic fibrosis. Nature, 274: 909 (1978).

22. Romeo, G., Parsons, M., Bossen, A., Blessing-Moore, J., and Cavalli-Sforza, L. L.: Binding of ${ }^{125} \mathrm{I}$-labeled proteinases to plasma proteins in cystic fibrosis. Pediatr. Res, 13: 1030 (1979).

23. Romeo, G., Denaro, M., and Parsons, M.: Competition for trypsin binding between $\alpha_{2}$-macroglobulin and antitrypsin antibodies in cystic fibrosis. J. Lab.
Clin. Med., 95: 116 (1980).

24. Salvesen, G. S. and Barrett, A. J.: Covalent binding of proteinases in their reaction with $\alpha_{2}$-macroglobulin. Biochem. J., 187: 695 (1980).

25. Schidlow, D. V. and Kueppers, F.: Trypsin binding activity of alpha ${ }_{2}$-macroglobulin in cystic fibrosis and other lung diseases. Am. Rev. Resp. Dis., 121: 31 (1980).

26. Shapira, E. and Menendez, R.: Increased binding of concanavalin A to $\alpha_{2^{-}}$ macroglobulin, IgM and IgG from cystic fibrosis plasma. Biochem. Biophys. Res. Commun., 93: 50 (1980)

27. Shapira, E., Ben-Yoseph, Y., and Nadler, H. L.: Decreased formation of $\alpha_{2^{-}}$ macroglobulin-protease complexes in plasma of patients with cystic fibrosis. Biochem. Biophys. Res. Commun., 71: 864 (1976).

28. Shapira, E., Rao, G. L. S., Wessel, H. U., and Nadler, H. L.: Absence of an $\alpha_{2-}$ macroglobulin-protease complex in cystic fibrosis. Pediatr. Res., 10:812 (1976).

29. Shapira, E., Ben-Yoseph, Y., and Nadler, H. L.: Abnormal breakdown of $\alpha_{2-}$ macroglobulin-trypsin complex in cystic fibrosis. Clin. Chim. Acta, 78: 359 (1977).

30. Shapira, E., Martin, C. L., and Nadler, H. L.: Comparison between purified $\alpha_{2-}$ macroglobulin preparations from normal controls and patients with cystic fibrosis. J. Biol. Chem., 252: 7923 (1977).

31. Sottrup-Jensen, L., Petersen, T. E., and Magnusson, S.: A thiol-ester in $\alpha_{2-}$ Macroglobulin cleaved during proteinase complex formation. FEBS Letters, 121: 275 (1980).

32. Swenson, R. P. and Howard, J. B.: Structural characterization of human $\alpha_{2-}$ macroglobulin subunits. J. Biol. Chem., 254: 4452 (1979).

33. Virca, G. D., Travis, J., Hall, P., and Roberts, R. C.: Purification of human $\alpha_{2^{-}}$ macroglobulin on cibacron blue sepharose. Anal. Biochem., 89: 274 (1978).

34. Weeke, B.: Crossed immunoelectrophoresis. Scand. J. Immunol., 2(Suppl 1): 47 (1973).

35. Wilson, G. B. and Fudenberg, H. H.: Studies on cystic fibrosis using isoelectric focusing. II. Demonstration of deficient proteolytic cleavage of $\alpha_{2}$-macroglobulin in cystic fibrosis plasma. Pediatr. Res., 10:87 (1976).

36. Zais, D. P. and Roberts, R. C.: System for simplified discontinuous-gradient polyacrylamide-gel electrophoresis. Clin. Chem., 23: 590 (1977).

37. Presented at the 20 th annual meeting of the Cystic Fibrosis Foundation, Atlanta GA, May 1979.

38. The present address of Dr. Lynn P. Nelles is: Division of Pharmaceutical Research, CIBA GEIGY, Basel, Switzerland. The present address of Dr. Guy S. Salvesen is: Department of Biochemistry, University of Georgia. Athens. GA 30601 . The present address of Philip K. Hall is: University of Wisconsin Center, Marshfield, WI.

39. The authors thank Dr. A. J. Barrett for useful discussions, Dr. Bradley Sullivan, pediatrician at the Marshfield Clinic for assistance in evaluating one of the $\mathrm{CF}$ patients, and Alice Stargardt for manuscript preparation.

40. Requests for reprints should be addressed to: Ronald C. Roberts, Ph.D., Marshfield Medical Foundation, 510 North St. Joseph Avenue, Marshfield, WI 54449.

41. This research was supported in part by a grant from the Cystic Fibrosis Foundation and a grant from the University of Wisconsin Center System.

42. Received for publication November 25, 1980

43. Accepted for publication August 20, 1981. 